\title{
COST ANALYSIS OF SPATIAL DATA PRODUCTION AS PART OF BUSINESS INTELLIGENCE WITHIN THE MAPPING DEPARTMENT
}

\author{
A.KISA ${ }^{1}$, B.ERKEK ${ }^{2}$, S.ÇOLAK ${ }^{3}$ \\ 'General Directorate of Land Registry and Cadastre, ANKARA,TURKEY- tk36756@tkgm.gov.tr \\ ${ }^{2}$ General Directorate of Land Registry and Cadastre, ANKARA, TURKEY- berkek@tkgm.gov.tr \\ ${ }^{3}$ General Directorate of Land Registry and Cadastre, ANKARA, TURKEY- tk36024@tkgm.gov.tr
}

\section{Commission II, WG II/3}

KEY WORDS: Data collection, BI, Reorganization, Reporting, Decision making

\begin{abstract}
Business intelligence is becoming an important strategic tool for business management. Companies have invested significant resources in applications for customer relationship management (CRM), supply chain management (SCM), enterprise resource planning (ERP), e-commerce, among others, which collect vast amounts of data. Today, these same companies are realizing that no matter how robust their application feature sets are, without an equally robust BI mechanism to make use of the collected data, these applications are ultimately coming up short. They do not provide actionable information to end users nor can they give a global understanding among all the organization's information from the various databases for accounting, CRM, and so on.
\end{abstract}

General Directorate of Land Registry and Cadastre (GDLRC) is the leader organizations in Turkey on the field of mapping-land registry-cadastre. GDLRC has executed spatial based projects on the way National Spatial Data Infrastructure especially from the beginnings of 2000s. such as; Continuously Operating GPS Reference Stations (TUSAGA-Aktif), Geo-Metadata Portal (HBB), Orthophoto-Base Map Production and web services, Completion of Initial Cadastre, Cadastral Renovation Project (TKMP), Land Registry and Cadastre Information System (TAKBIS), Turkish National Spatial Data Infrastructure Project (TNSDI), Ottoman Land Registry Archive Information System (TARBIS). Most of this project has been completed. Some software has been developed within the mentioned project, especially reporting for management level to take decision.

In the year of 2010 a new law launched and forced to reorganization of General Directorate of Land Registry and Cadastre. The new structural changes effected to whole organization, management understanding, carrier understanding so on. Even in mapping department which is spatial data producer, now there is no technician, there is no section; there are new carrier as experts. Because of that, all procedures and performance critters are redefined, improvement of existing software are defined, cost analysis implemented as a part of business intelligence. This paper indicated some activities such as cost analysis and its reflection in Mapping Department as an example to share in the concept of reorganization.

\section{INTRODUCTION}

The quantitative and qualitative increase in spatial data production shows parallelism with the improved technology. In spite of its advantages, it is possible that disadvantages will be encountered in case costs are not truly introduced, managed and updated information is not reached on time. The importance of business intelligence in production of spatial data rises at this point. The examples of business intelligence in production of spatial data are; Enterprise Resource Planning (ERP), Investment Monitoring, Directorate of Strategy Development (sgb.net) and On Line Analytic Processing (OLAP) Cubes. It is possible to monitor annual changes in costs with the help of these programs.

\section{PROJECTS CARRIED ON BY GDLRC}

Projects carried on by GDLRC will provide many opportunities to state institutions and organizations together with private sector. Besides, huge profit will be obtained in terms of costs. Since these projects collect up-to-date data and provide reliable reporting, decision making will be done more effectively. As a result of this, great contributions will be attained in the reorganization of state institutions and organizations together with private sector.

\subsection{TUSAGA-Aktif Project}

The purpose of this project is to determine geographical position in real time (RTK) for 24 hours with $\mathrm{cm}$ accuracy across Turkey and Turkish Republic of North Cyprus and to transform existing maps into the International Coordinate System (ITRF). Within the frame of the project, 146 TUSAGAAktif stations were established across Turkey and Turkish Republic of North Cyprus. Besides, control centers were established in GDLRC and General Command of Mapping (GCM).

The ability of determining coordinates in $\mathrm{cm}$ accuracy within few seconds is provided across Turkey and Turkish Republic of North Cyprus. As a result;

- It is not needed to establish and survey benchmarks which form the $30 \%$ of the mapping and cadastre works in terms of both time and cost and it is envisaged to achieve savings about 75 million TL annually from the 250 million TL source allocated to mapping works.

- Cost and time savings are provided at data collecting activities in many e-state applications (e-municipality, etransportation, Land Registry and Cadastre Information System etc.)

- Transformation parameters are defined by doing surveys from TUSAGA-Aktif on common points by raster 
transformation method for the purpose of datum transformation done between ED-50 and ITRFxx.

- Tectonic plate moves in Turkey, which is located on seismic belts, is monitored and online data with $\mathrm{mm}$ accuracy is provided to academic works done in the purpose of contributing early warning systems.

- Works have been started by the General Directorate of Meteorology in order to model atmosphere (ionosphere and troposphere) and make meteorological predictions as well as determine water vapor quantity which can be transformed into precipitation.

\subsection{Geo-Metadata Portal Project}

Geo-Metadata Portal (HBB) and Large Scale Map and Map Information Production Regulation imposed the obligation of recording intended, ongoing or completed map and map information and getting project record number in order to provide appropriate use of country resources and prevention of repetitive production and monitoring of map and map information to the ministries, state institutions \& organizations and municipalities. With respect to articles $103^{\text {rd }}, 104^{\text {th }}$ and $105^{\text {th }}$ of the regulation, a web-based metadata portal was designed by GDLRC taking ISO 19115 standards into consideration. It was announced to relevant state institutions \& organizations on $07 / 07 / 2008$ and presented to online service at http://hbb.tkgm.gov.tr/metadata/.

It was put into service to let all organizations enter their metadata on internet which produce map and map information. Entering and querying metadata, querying 1/5000 scale standard topographic map sheet, querying up-to-date point numbers and approximate coordinates of ground control points and analyzing ground control point location determination studies of the project whose software was already completed are able to be done on web.

\subsection{Orthophoto - Base Map Production and Web Services}

The presentation of Digital Cadastre Studies and big scale engineering works with 1/5000 scale orthophoto base maps and web services are continuing with the aim of quality-integrity controls and composing legislative bases in decision support procedures.

The acquisition of Digital Aerial Camera, Photogrammetric and Image Storage Software and Hardware with the aim of aerial image provision; improved the flight capacity and provided $26 \%$ decrease in expenses.

\subsection{Cadastral Renovation Project (TKMP)}

The project is set up for providing the use and updating of current land registry-cadastre information in legislative and digital formats with the structure that composes as base for Spatial Information Systems as foreseen in Cadastre Law.

Based on the needs of the areas which are shorthanded in means of daily requirements, 22 Region Offices of GDLRC, are working for updating the "Cadastre Maps and Information" along with transferring "Screw Plate and Technical Archive Data to Digital Environment" in order to provide base for Spatial Information System.

\subsection{Land Registry and Cadastre Information System (TAKBIS)}

TAKBIS is an integrated system that aims at monitoring and controlling of individual and public properties efficiently; keeping this information in a secure area and accessing the information safely by transferring land registry and cadastre records to computer environment for carrying out all activities on computer infrastructure. With this project; standardization, minimization of the errors, security, reliability, accountability, ease in inspection, instant and actual data, integration, quality etc. will be provided.

\subsection{Turkish National Spatial Data Infrastructure Project (TNSDI)}

As mentioned in the $75^{\text {th }}$ activity; under Modernization of Public Administration action plan of Information Community Strategy that is published and inured in 28/07/2006 with the number of 26242 in Official Gazette, which foresees the presentation of data where it is produced; Constitution of Geographic Information Infrastructure project is carried out under the authority of GDLRC.

TNSDI is an e-state project aiming at constitution of a national level GIS infrastructure in accordance with technological improvements and INSPIRE directives; composing of a web portal for the public corporation and institutions to present their data to recipients on the common infrastructure; constitution of data standards in regard to cover the requirements of the all user institutions and establishment of geographic data exchange standards.

TURKSAT A.Ş. is contracted in 16/12/2009 for the feasibility assessment of the project. After the feasibility assessment is completed, constitution of web portal studies will be started.

\subsection{Land Registry Archive Information System (TARBIS)}

With TARBIS project, a big portion of the documents under the responsibility of Department of Land Registry Archive of GDLRC, are transferred to digital environment and microfilms; thus it is provided to keep and use the documents efficiently. TARBIS applications can record statistics on the usage and movement of the documents, create reports and supply data to the demanding individuals or corporations in digital or hard copy format.

\section{BUSINESS INTELLIGENCE EXAMPLES}

\subsection{Enterprise Resource Planning (ERP)}

ERP is the general definition for comprehensive management systems providing efficient use of manpower, machinery and equipment required for production of goods and services. ERP systems are generally easy to use and aim at bringing or supporting to bring all data and processes of an enterprise together. Enterprises, non-profit organizations, foundations, governments or other institutions can use ERP systems.

In TAKBIS project carried out by GDLRC; ERP software package includes; incoming-outgoing documents, overtime, supplementary payments, project compensation payments, promoted personnel list, permissions, personnel information and etc. An ERP system avoids the user to face two or more software interface and provides additional advantages. It procures software standardization, use of single software instead 
of more than one, availability to easily and effectively report creation and stocktaking. ERP targets at all units and functions to be integrated in a single computer system for covering the needs of special departments. This integrated approach provides a high amount of feedback when the software is setup and used correctly.

\subsection{Investment Monitoring System}

Investment Monitoring System is a web based software aiming at monitoring the tenders made by GDLRC for projects such as digital cadastre and renovation. Thus the actuality of the information is procured and gains in both time and safety aspects are provided. The system affects the expenditure in positive way as well as supplying information required for fast and reliable reports in means of business intelligence.

\subsection{SGB net}

Strategic management that constitutes the essence of Law No 5018 , together with an understanding of the new public financial management, including performance-based budgeting and internal control systems, and thanks to SGB.net System, which allows to implement these activities, data related to public services and work processes is converted to information in the digital environment and this information is included in the decision making processes to create policy. The system is designed to cover all financial processes, applicable to all public administrations and structured that can work in an integrated way with other systems.

Since it is a web-based system, it has a substructure that everyone can easily access without any extra cost and there is no installation cost. The most important feature of the system is for the first time a public authority is developed a way not only for its own use but also for the use of other public administrations. In this way the public administrations can use any sub-system or the whole system by adapting their business processes the system free of charge.

Using this program GDLRC prevented the duplication of investments; savings were achieved both in terms of time and in financial terms. Planning, implementation, monitoring and control components form the basis of the system, thus a link is established between plan and implementation, application and monitoring, monitoring and control. In this context, each component is supported by various developed modules. These modules are: The Library Module, Receivable Tracking Module, Chattel Registration Module, Expenditure Management Module, Budget Preparation Module, Budget Processes Module, Performance Budget Module, Internal/Preliminary Financial Control Module, Document Management Module, Identity Sharing Module, and User Management Module.

\subsection{On Line Analytic Processing (OLAP) Cubes}

Work done by staff employed by the company and work periods are defined. The web-based software is developed for tracking tasks and timelines. Each employee records the work done and duration of the work performed to the system.

Via OLAP reports, the institution top manager can view how any staff spends the day, how the pace of the work is and the behavior characteristics and so on as a report based on careers, units and time intervals. In this way it could be more efficient in terms of management. For instance, performance management, resource management, work flow management, etc. is easier. With these reports, people could be managed more effectively, individuals might be utilized more effectively and in terms of work the most appropriate people can be determined.

OLAP means intervention to the costs in the large means in terms of immediate intervention of human resources for the disruptions to the works in progress or in planning, or projects.

\section{COST ANALYSIS}

It is difficult to separate costs in public sector. The biggest reason for that is the lack of profit for the public sector. However, changes in the production costs can be observed by comparing technological developments and changes with its resulting production. It is not hard to predict that projects mentioned above provide large gains during years.

Comparison of the spatial data production will be done with respect to years in order to observe improvements in production cost and to have an idea.

\subsection{Spatial Data Production}

\begin{tabular}{|c|c|c|}
\hline YEAR & KM $^{2}$ & KM/TUL \\
\hline 2001 & 3142 & \\
\hline 2002 & 4860 & \\
\hline 2003 & 759 & \\
\hline 2004 & 3582 & \\
\hline 2005 & 15660 & 77 \\
\hline 2006 & 2398 & 50 \\
\hline 2007 & 1172 & \\
\hline 2008 & 5967 & 75 \\
\hline 2009 & 6800 & \\
\hline 2010 & 68633 & \\
\hline 2011 & 55572 & 150 \\
\hline TOTAL & $\mathbf{1 6 8 5 4 5}$ & $\mathbf{3 5 2}$ \\
\hline
\end{tabular}

Table 1: The quantity of aerial photography acquisition in the last decade

It can be seen from the table above that there is a great increase in acquisition of aerial photos after 2009. Climate and weather conditions, of course, cannot make such a big impact. The biggest reason for the increase is using digital photogrammetric systems instead of analog devices for the production.

Processing steps such as rolling, bath-printing etc. in the production of maps done by analog devices do not exist in digital systems. Besides, error rate is less at analog system compared to digital system, because the calculations in digital system are adjusted automatically. This means cost and time savings which can be easily seen. 


\section{CONCLUSIONS AND RECOMMENDATIONS}

As discussed in detail, each project for the production of spatial data, to transform into opportunities in the future considering the potential benefits and areas of use is high. These projects are inextricably linked with the technology.

Although, the price is high in terms of product technology, it can be seen from the table that the technological costs will pay for it.

Business intelligence is of paramount importance here. Examples of business intelligence are used to form the base for each project mentioned above. Errors encountered in the business intelligence programs are used in the workflow to take precautions and to be able to intervene immediately, logistics, time savings, and the prevention of waste of resources as efficiently and effectively use the audit as a result of ease and a lot of healthy benefits, such as statistical information have emerged. This means doing it with an effective method and the lowest cost.

Both qualitative and quantitative production of spatial data was more to get the product is expected to be more advantageous to use the latest technology. If, however, to consider the mess that has brought the technology, business intelligence base must be necessarily established. This is because the technology is not always easy to adapt to the innovations at the time. Created a good base of business intelligence on demand for the production of new technological developments, bad management of spatial data can turn an advantage into a disadvantage. In addition to the production of each technical error that should be noted that the extra cost.

Although, it is thought that technological advances in spatial data production provide qualitative and quantitative increase in business intelligence, it can make a reverse impact in case business intelligence is not formed and cost analysis is not done well in accordance.

\section{REFERENCES}

1) www.tkgm.gov.tr

2) www.maliye.gov.tr 